\title{
Helicobacter pylori eradication shifts monocyte Fc $\gamma$ receptor balance toward inhibitory FcyRIIB in immune thrombocytopenic purpura patients
}

\author{
Atsuko Asahi,1,2 Tetsuya Nishimoto, ${ }^{1}$ Yuka Okazaki, ${ }^{1}$ Hidekazu Suzuki, ${ }^{3}$ Tatsuhiro Masaoka, ${ }^{3}$ \\ Yutaka Kawakami, ${ }^{4}$ Yasuo Ikeda, $^{2}$ and Masataka Kuwana ${ }^{1}$ \\ ${ }^{1}$ Division of Rheumatology, ${ }^{2}$ Division of Hematology, and ${ }^{3}$ Division of Gastroenterology and Hepatology, Department of Internal Medicine, and \\ ${ }^{4}$ Institute for Advanced Medical Research, Keio University School of Medicine, Tokyo, Japan.
}

\begin{abstract}
Immune thrombocytopenia purpura (ITP) is a bleeding disorder in which platelet-specific autoantibodies cause a loss of platelets. In a subset of patients with ITP and infected with Helicobacter pylori, the number of platelets recovers after eradication of $\mathrm{H}$. pylori. To examine the role of $\mathrm{H}$. pylori infection in the pathogenesis of ITP, the response of 34 ITP patients to treatment with a standard $H$. pylori eradication regimen, irrespective of whether they were infected with $\mathrm{H}$. pylori, was evaluated. Eradication of $\mathrm{H}$. pylori was achieved in all $\mathrm{H}$. pyloripositive patients, and a significant increase in platelets was observed in $61 \%$ of these patients. By contrast, none of the $\mathrm{H}$. pylori-negative patients showed increased platelets. At baseline, monocytes from the H. pylori-positive patients exhibited an enhanced phagocytic capacity and low levels of the inhibitory Fc $\gamma$ receptor IIB (Fc $\gamma$ RIIB). One week after starting the $H$. pylori eradication regimen, this activated monocyte phenotype was suppressed and improvements in autoimmune and platelet kinetic parameters followed. Modulation of monocyte Fc $\gamma \mathbf{R}$ balance was also found in association with $\mathrm{H}$. pylori infection in individuals who did not have ITP and in mice. Our findings strongly suggest that the recovery in platelet numbers observed in ITP patients after $H$. pylori eradication is mediated through a change in Fc $\gamma R$ balance toward the inhibitory Fc $\gamma$ RIIB.
\end{abstract}

\section{Introduction}

Immune thrombocytopenia purpura (ITP) is an autoimmune disorder caused by increased platelet clearance by anti-platelet autoantibodies (1). In 1998, Gasbarrini et al. reported increase in platelet count in ITP patients infected with Helicobacter pylori after successful eradication of this bacterium (2). Recent accumulating evidence in Italy and Japan indicates that the eradication of $H$. pylori is effective in increasing the platelet count in nearly half of $H$. pylori-infected patients with idiopathic ITP $(3,4)$. In addition, a recent report showed that this platelet response lasts for years and cases of relapse are few (5). Based on its efficacy, good safety profile, and low cost, $H$. pylori eradication therapy for adult ITP is becoming very popular in several countries. Some investigators have suggested that the efficacy of $H$. pylori eradication in ITP patients may be mediated by $H$. pylori-independent mechanisms, such as immunomodulatory effects of the drugs used for the regimen (3), but we recently reported its complete lack of efficacy in H. pylori-uninfected ITP patients in a prospective study in which the patients were treated with a standard $H$. pylori eradication regimen irrespective of their $H$. pylori infection status (6). This finding clearly indicates that the platelet recovery observed in ITP patients after the eradication regimen results from the disappearance of $H$. pylori itself.

Nonstandard abbreviations used: CagA, cytotoxin-associated gene A; Fc RIIB, Fc receptor IIB; GPIIb/IIIa, glycoprotein IIb/IIIa; ITP, immune thrombocytopenia purpura; RES, reticuloendothelial system; TPO, thrombopoietin.

Conflict of interest: The authors have declared that no conflict of interest exists. Citation for this article: J. Clin. Invest. 118:2939-2949 (2008). doi:10.1172/JCI34496.
Several hypotheses have been proposed regarding the mechanism by which $H$. pylori might induce the development of ITP. One is that Abs to $H$. pylori components cross-react with platelet surface antigens. In this regard, Takahashi et al. reported that platelet eluates from $H$. pylori-positive ITP patients recognized the cytotoxinassociated gene $\mathrm{A}$ (CagA), one of the $H$. pylori-derived proteins that determine bacterial virulence (7), although another group demonstrated that platelet eluates from $H$. pylori-positive ITP patients that reacted with glycoprotein IIb/IIIa (GPIIb/IIIa) or GPIb failed to recognize $H$. pylori antigens (8). Another potential mechanism is modulation of the host's immune system by $H$. pylori in a manner that promotes the emergence of autoreactive B cells (9). However, no significant difference between $H$. pylori-positive and $H$. pylori-negative individuals has been found for non-organ-specific autoantibody responses, such as anti-nuclear, anti-microsome, or anti-smooth muscle Abs (10). Despite these findings, the role of $H$. pylori infection in the pathogenesis of ITP remains obscure. These previous studies focused on anti-platelet Ab production in association with $H$. pylori infection, but potential effects of $H$. pylori infection on the platelet clearance process in ITP patients have not been assessed. In this study, to elucidate the mechanism responsible for platelet recovery in ITP patients after the successful eradication of $H$. pylori, we conducted a prospective study in which factors potentially associated with the pathogenic processes of ITP, i.e., autoimmune responses to the major platelet antigen GPIIb/IIIa, parameters associated with platelet turnover, and the phenotypic and functional properties of phagocytes, were serially measured in ITP patients who were treated with a standard eradication regimen, irrespective of their $H$. pylori infection status. 


\begin{tabular}{|c|c|c|c|}
\hline $\begin{array}{l}\text { Demographics and } \\
\text { laboratory findings }\end{array}$ & $\begin{array}{c}\text { H. pylori positive } \\
(n=23)\end{array}$ & $\begin{array}{l}H . p y l o r i \text { negative } \\
(n=11)\end{array}$ & $P$ \\
\hline Sex (\% female) & 52 & 73 & NS \\
\hline Age at visit (yr) & $59.7 \pm 11.9$ & $48.0 \pm 17.8$ & NS \\
\hline Disease duration (yr) & $7.5 \pm 6.7$ & $8.3 \pm 6.6$ & NS \\
\hline \multicolumn{4}{|l|}{ Current treatment ${ }^{A}$} \\
\hline Prednisolone ${ }^{\mathrm{B}}$ & $35 \%$ & $45 \%$ & NS \\
\hline Danazol & $0 \%$ & $18 \%$ & NS \\
\hline Splenectomy & $4 \%$ & $45 \%$ & 0.01 \\
\hline Mean platelet count $\left(\times 10^{9} / l\right)$ & $42 \pm 23$ & $31 \pm 13$ & NS \\
\hline
\end{tabular}

APercentages indicate the percentage of patients who were currently using the treatment. BMean daily dosage in $\mathrm{H}$. pylori-positive and -negative patients was $4.8 \mathrm{mg}$ (range 3-7.5) and $4.8 \mathrm{mg}$ (range 4-5), respectively. Data are group means \pm SD.

Our findings demonstrate that the platelet recovery observed in ITP patients after $H$. pylori eradication is associated with modulation of the monocyte $\mathrm{Fc} \gamma$ receptor balance toward the inhibitory $\mathrm{Fc} \gamma$ receptor IIB (Fc $\gamma \mathrm{RIIB})$.

\section{Results}

Patient characteristics. Thirty-four consecutive patients with ITP (14 males and 20 females, aged 24 to $73 \mathrm{yr}$ ) were enrolled in this open-label, prospective study. $H$. pylori infection was detected in 23 patients (68\%). Comparison of the pretreatment clinical characteristics of the H. pylori-positive and -negative patients (Table 1) showed the $H$. pylori-positive patients tended to be older than the $H$. pylori-negative patients $(P=0.08)$. Some patients took lowdose prednisolone ( $\leq 7.5 \mathrm{mg}$ daily), but there was no difference in the frequency or the mean dosage between $H$. pylori-positive and -negative patients. A history of splenectomy was significantly less frequent in the $H$. pylori-positive patients compared with the $H$. pylori-negative patients, indicating that refractory cases were more common in the H. pylori-negative patients.

Immunologic and platelet turnover parameters before treatment in ITP patients with and without $H$. pylori infection. A total of 11 immunologic and platelet turnover parameters, including anti-GPIIb/IIIa Abproducing B cells, platelet-associated anti-GPIIb/IIIa Abs, T cell responses induced by GPIIb/IIIa and tetanus toxoid, the proportion of reticulated platelets, the circulating thrombopoietin (TPO)

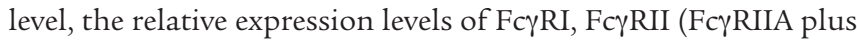
Fc $\gamma$ RIIB), Fc $\gamma$ RIII, and CD86 on circulating monocytes, and the nonspecific phagocytosis of circulating monocytes were compared between ITP patients with and without H. pylori infection (Figure 1). We evaluated the proportion of monocytes expressing Fc $\gamma$ RIII instead of its expression level because only a small subset of the peripheral blood monocytes expressed this Fc $\gamma$ R.

There was no difference in the frequency of anti-GPIIb/IIIa $\mathrm{Ab}$-producing $\mathrm{B}$ cells or platelet-associated anti-GPIIb/IIIa Ab levels between the 2 groups. In contrast, $H$. pylori-positive patients showed a more prominent $\mathrm{T}$ cell response to GPIIb/IIIa compared with $H$. pylori-negative patients, and there was no difference in the degree of the response to tetanus toxoid, an irrelevant foreign recall antigen. The proportion of reticulated platelets was significantly greater in the H. pylori-positive patients than in the H. pylori-nega- tive patients. In circulating monocytes, the expression of Fc $\gamma$ RII, including both activating Fc $\gamma$ RIIA and inhibitory Fc $\gamma$ RIIB, was lower in the H. pylori-positive patients than the H. pylori-negative patients. Moreover, the expression of activating FcyRI tended to be upregulated in the H. pyloripositive patients $(P=0.06)$. Finally, monocytes from the $H$. pylori-positive patients exhibited an enhanced phagocytic capacity compared with those from the $H$. pylori-negative patients, suggesting an activated monocyte phenotype predominated in the H. pylori-positive patients.

Platelet response to the $H$. pylori eradication regimen. All 34 patients completed a 7-day standard eradication regimen that consisted of amoxicillin, clarithromycin, and lansoprazole regardless of whether they were positive for $H$. pylori infection. Adverse events potentially related to the therapy were observed in 10 patients (29\%): abdominal pain and/or diarrhea in 9 and skin rash in 1 . All the symptoms resolved quickly after the regimen ended. Eradication was successful in all $23 \mathrm{H}$. pylori-positive patients, and 14 (61\%) of them were classified as responders. In contrast, none of the 11 $H$. pylori-negative patients showed an increased platelet count. These frequencies were significantly different $(P=0.001)$. The platelet counts 0,12 , and $24 \mathrm{wk}$ after initiation of the eradication regimen in $H$. pylori-positive responders and nonresponders, and in H. pylori-negative patients are shown in Figure 2. Some H. pyloripositive nonresponders showed a slight increase in platelet count, but almost no fluctuation in platelet count was observed in the H. pylori-negative patients. During the 24 -wk period, prednisolone dosage was reduced in 2 responders at $12 \mathrm{wk}(7.5$ to $5 \mathrm{mg}$ and 5 to $2.5 \mathrm{mg}$ ), but the stable dosage was given in the remaining patients.

Serial changes in immunologic and platelet turnover parameters after H. pylori eradication. Immunologic and platelet turnover parameters measured prior to treatment were serially examined 12 and $24 \mathrm{wk}$ after initiation of the eradication regimen in the $H$. pylori-positive responders and nonresponders and in the $H$. pylori-negative patients (Figure 3). The anti-GPIIb/IIIa Ab-producing B cells and platelet-associated anti-GPIIb/IIIa Abs were significantly reduced at 12 and $24 \mathrm{wk}$ in the $H$. pylori-positive responders. The proportion of reticulated platelets was also significantly reduced in the H. pylori-positive responders. Similar but weak trends were observed in the H. pylori-positive nonresponders but not in the H. pylori-negative patients. The peripheral blood $\mathrm{T}$ cell response to GPIIb/IIIa tended to be suppressed in the H. pylori-positive responders $(P=0.09)$, while there was no fluctuation in the response to tetanus toxoid. In monocytes from $H$. pylori-positive responders, their baseline upregulated $\mathrm{Fc} \gamma \mathrm{RI}$ expression decreased and the downregulated Fc $\gamma$ RII (Fc $\gamma$ RIIA plus Fc $\gamma$ RIIB) expression increased to the levels of monocytes from $H$. pylori-negative patients after H. pylori eradication. In contrast, the proportion of $\mathrm{Fc} \gamma \mathrm{RIII}$-positive monocytes and CD86 expression levels on monocytes were stable in all 3 groups during the study period. The enhanced phagocytic capacity of monocytes in $H$. pylori-positive responders was significantly reduced after $H$. pylori eradication, reaching the level of $H$. pylori-negative patients. These changes in the monocyte phenotype were not observed in the $H$. pylori-positive nonresponders or in the H. pylori-negative patients. The IgG anti-CagA Ab level gradually reduced following the eradication regimen in the H. pylori-positive patients irrespective of the platelet response, but samples were still positive for anti-CagA Ab even at 12 and $24 \mathrm{wk}$, when the platelet count had nearly fully recovered. 

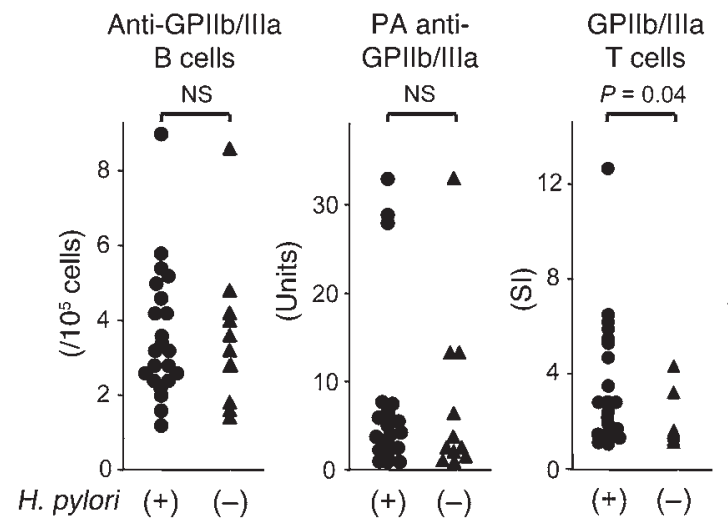

$(+)(-)$

$(+)(-)$

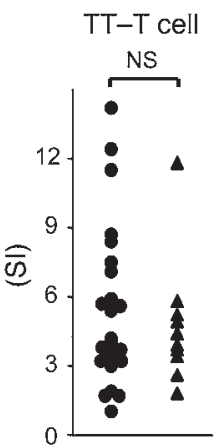

$(+)(-)$

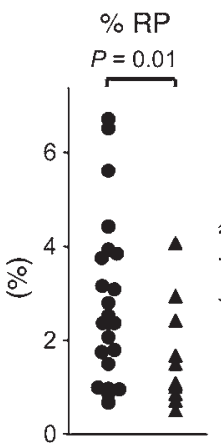

$(+)(-)$

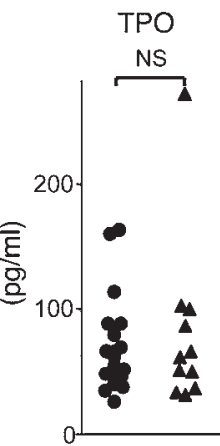

$(+) \quad(-)$
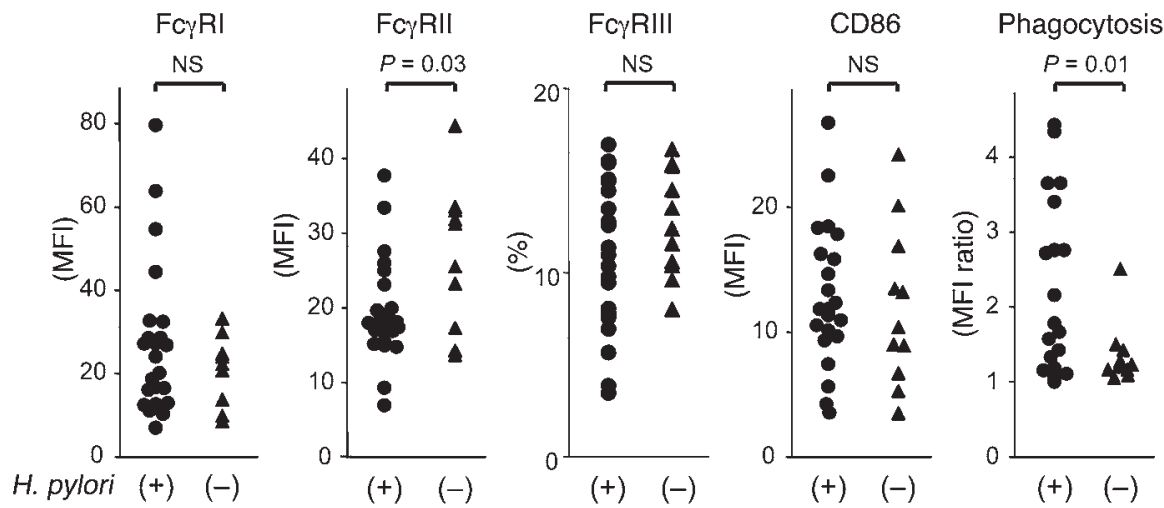

Figure 1

Immunologic and platelet turnover parameters prior to treatment in ITP patients with or without $H$. pylori infection. The anti-GPIIb/Illa Ab-producing B cells, platelet-associated (PA) anti-GPIIb/IIla Abs, GPIIb/IIla-specific T cell response, tetanus toxoid-specific (TT-specific) T cell response, pro-

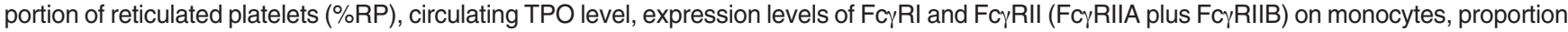
of FcyRIII-positive monocytes, expression level of CD86 on monocytes, and nonspecific phagocytosis of monocytes were compared among 23 ITP patients infected with $H$. pylori and 11 ITP patients who were not infected with $H$. pylori. Expression of FcyRll was examined using mAb clone

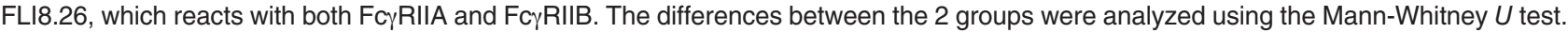

In the $H$. pylori-positive responders, after the eradication of H. pylori, the parameters for $\mathrm{T}$ and $\mathrm{B}$ cell responses to platelet antigens and platelet turnover improved, and the activated monocyte phenotype was suppressed, as the platelet count increased. To examine which parameter changed first, we further evaluated these parameters at $1 \mathrm{wk}$, when the eradication regimen had just ended, in the $14 \mathrm{H}$. pylori-positive responders
(Table 2). The platelet count was significantly increased at $1 \mathrm{wk}$, consistent with a previous report (5). At this time point, the phagocytic capacity of monocytes was the only parameter that had changed from its pretreatment level.

In $3 \mathrm{H}$. pylori-positive patients who were untreated and whose platelet count was $>50 \times 10^{9} / 1$ at study entry, 2 were responders and the remaining 1 was a nonresponder. When these 3 patients

\section{Figure 2}

Serial platelet counts before and after initiation of the $\mathrm{H}$. pylori eradication regimen in $14 \mathrm{H}$. pylori-positive ITP responders, $9 \mathrm{H}$. pylori-positive ITP nonresponders, and $11 \mathrm{H}$. pylori-negative ITP nonresponders. Changes in the absolute values 12 and 24 wk from the baseline value taken at wk 0 were assessed by paired $t$ test. ${ }^{*} P<0.01$ compared with wk 0 .

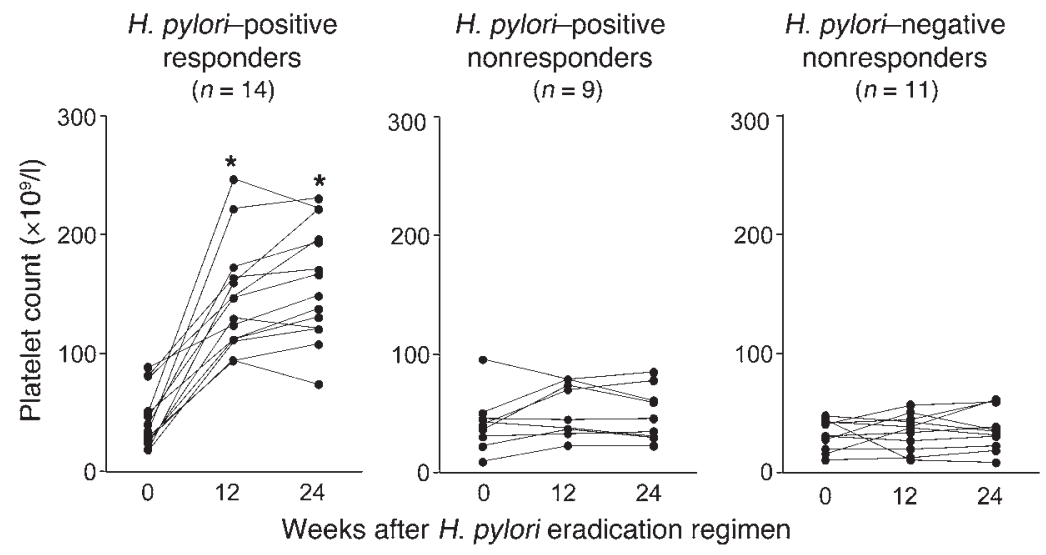



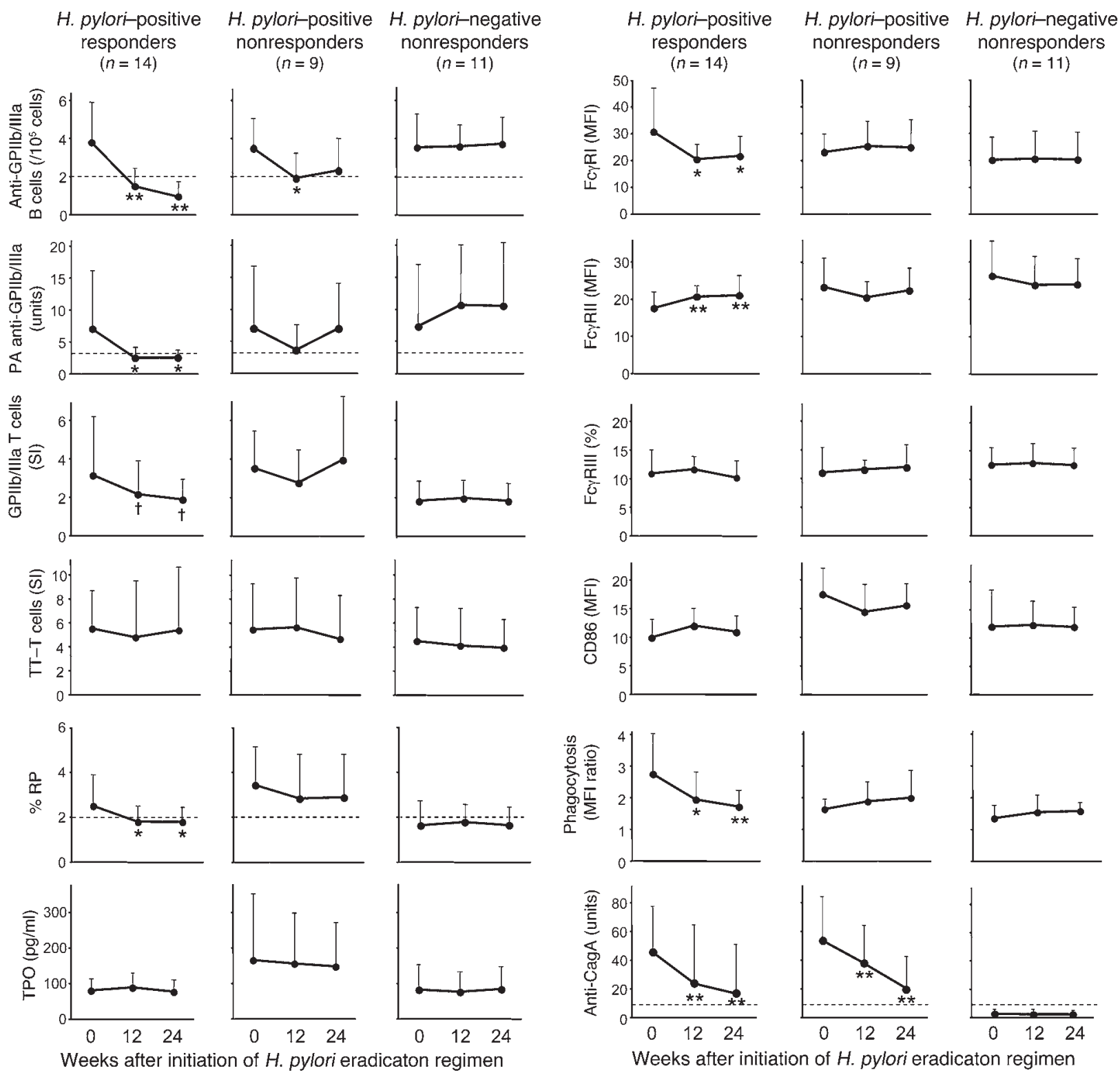

Figure 3

Serial measurements of immunologic and platelet turnover parameters before and after the $\mathrm{H}$. pylori eradication in $14 \mathrm{H}$. pylori-positive ITP responders, $9 \mathrm{H}$. pylori-positive ITP nonresponders, and $11 \mathrm{H}$. pylori-negative ITP nonresponders. Anti-GPIlb/Illa Ab-producing B cells, plateletassociated anti-GPIlb/llla Abs, GPIlb/IIla-specific T cell response, tetanus toxoid-specific T cell response, proportion of reticulated platelets, circu-

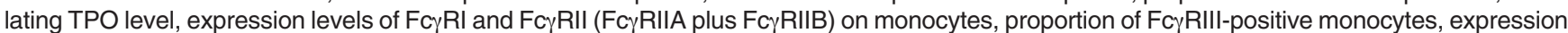
level of CD86 on monocytes, nonspecific phagocytosis of circulating monocytes, and anti-CagA Ab levels were measured prior to treatment and 12 and 24 wk after initiation of the H. pylori eradication regimen. Expression of FcyRII was examined using mAb clone FLI8.26, which reacts with both Fc $\gamma$ RIIA and FcyRIIB. Results are shown as the mean + SD. Changes in the values at 12 and 24 wk from the baseline value measured at wk 0 were assessed by paired $t$ test. Dotted lines indicate the cut-off values: 2.0 for anti-GPIlb/llla Ab-producing B cells; $3.3 \mathrm{U}$ for platelet-associated anti-GPIIb/IIla Abs; $2.0 \%$ for \% RP; and $7.5 \mathrm{U}$ for anti-CagA Ab. ${ }^{\dagger} P<0.1,{ }^{*} P<0.05$, and ${ }^{* *} P<0.01$ compared with wk 0 .

were excluded from the analysis, concordant results regarding changes in the monocyte phenotype were obtained.

Change in the Fc $\mathrm{RIIA} / \mathrm{IIB}$ balance of monocytes after $\mathrm{H}$. pylori eradication. In humans, 2 types of Fc $\gamma \mathrm{RII}$ are expressed on monocytes: an activating receptor, Fc $\gamma$ RIIA, and an inhibitory receptor, Fc $\gamma$ RIIB (11). Because the extracellular domains of FcyRIIA and FcyRIIB are highly homologous, we measured the mRNA expression levels of FcyRIIA and FcyRIIB on sorted monocytes independently, by quantitative PCR, using specific primers for the intracellular domains of these Fc $\gamma$ Rs. The results revealed that the FcyRIIA/IIB mRNA expression ratio was significantly higher in the H. pyloripositive than the $\mathrm{H}$. pylori-negative patients prior to treatment (Figure 4A). In the H. pylori-positive responders, the FcyRIIA/IIB ratio was significantly decreased at 1 and $12 \mathrm{wk}$, but this change was not observed in the H. pylori-positive nonresponders or in the H. pylori-negative patients (Figure 4B). When the protein expression 


\section{Table 2}

Serial measurement of ITP-related parameters before and 1 wk after the $H$. pylori eradication regimen in $14 \mathrm{H}$. pylori-positive responders

\section{ITP-related parameter}

Platelet count $\left(\times 10^{9} / l\right)$

Anti-GPIIb/Illa Ab-producing B cells (/105 PBMCs)

Platelet-associated anti-GPIIb/IIla Abs (U)

GPIIb/IIla-induced T cell response (SI)

Tetanus toxoid-induced T cell response (SI)

Reticulated platelets (\%)

Plasma TPO (pg/ml)

$\mathrm{Fc} \gamma \mathrm{RI}$ expression on monocytes (MFI)

FcyRII expression on monocytes (MFI)A

Proportion of Fc $\gamma$ RIII-positive cells (\%)

CD86 expression on monocytes (MFI)

Non-specific phagocytosis of monocytes (MFI ratio)

Prior to treatment
$42.9 \pm 23.6$
$3.8 \pm 2.1$
$7.1 \pm 9.2$
$3.4 \pm 3.2$
$5.7 \pm 3.3$
$2.4 \pm 1.6$
$79.1 \pm 40.5$
$31.0 \pm 21.7$
$17.2 \pm 4.8$
$10.9 \pm 4.0$
$9.8 \pm 3.5$
$2.8 \pm 1.5$

$\begin{array}{cc}\text { 1 wk after treatment } & \boldsymbol{P} \\ 68.6 \pm 32.8 & 0.003 \\ 3.6 \pm 1.7 & \text { NS } \\ 7.1 \pm 8.7 & \text { NS } \\ 3.5 \pm 3.4 & \text { NS } \\ 5.4 \pm 4.1 & \text { NS } \\ 2.6 \pm 3.0 & \text { NS } \\ 78.2 \pm 40.7 & \text { NS } \\ 27.1 \pm 20.2 & \text { NS } \\ 18.1 \pm 3.7 & \text { NS } \\ 11.0 \pm 3.0 & \text { NS } \\ 10.1 \pm 5.4 & \text { NS } \\ 1.8 \pm 0.5 & 0.008\end{array}$

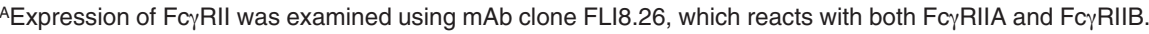
Results shown are the mean $\pm \mathrm{SD}$. SI, stimulation index.

ication was successful in 7 subjects, but not in 2 . As expected, there was no substantial change in the platelet count during the observation period in any subject. In monocytes from the successfully treated individuals, there were trends toward downregulated Fc $\gamma$ RI expression and phagocytic capacity and toward upregulated $\mathrm{Fc} \gamma \mathrm{RII}$ (Fc $\gamma$ RIIA plus Fc $\gamma$ RIIB) expression $12 \mathrm{wk}$ after the eradication, as observed in the $H$. pyloriinfected ITP responders, but these changes were not statistically significant (Figure 5). The lack of significance appears to be due to the highly variable responses among individuals. It is of note that the subjects with

of FcyRIIB on monocytes was examined by flow cytometry using mAbs specific to the intracellular domain of this molecule, Fc $\gamma$ RIIB expression was increased at $12 \mathrm{wk}$ in a representative $H$. pylori-positive responder but not in a nonresponder (Figure 4C). As a result, Fc $\gamma$ RIIB expression was significantly upregulated at $12 \mathrm{wk}$ in $H$. pylori-positive responders, but this change was not observed in the H. pylori-positive nonresponders or in the H. pylori-negative patients (Figure 4D). These findings indicate that a change in the Fc $\gamma$ R balance toward the inhibitory Fc $\gamma$ RIIB, together with a diminished phagocytic capacity of the monocytes, is the first event that occurs as a result of the $H$. pylori eradication in responders.

We further examined a potential role of Th1/Th2 balance in regulating $\mathrm{F} c \gamma \mathrm{R}$ expression profiles on monocytes in association with $H$. pylori infection (11), but there was no substantial change in the ratio of IFN- $\gamma^{+} \mathrm{CD} 4^{+} \mathrm{T}$ cells to $\mathrm{IL}-4^{+} \mathrm{CD} 4^{+} \mathrm{T}$ cells in circulation prior to treatment and $12 \mathrm{wk}$ after initiation of the eradication regimen in the $H$. pylori-positive responders $(2.6 \pm 1.3$ and $2.7 \pm 1.3$, respectively), the $H$. pylori-positive nonresponders ( $3.1 \pm 0.6$ and $3.7 \pm 1.0$, respectively), or the $H$. pylori-negative patients $(3.4 \pm 1.1$ and $3.5 \pm 1.5$, respectively).

Parameters that predict the platelet response to $H$. pylori eradication. To examine which parameters predict the platelet response to the eradication of H. pylori in ITP patients, patient characteristics, the immunologic and platelet turnover parameters listed in Figure 1, as well as the IgG anti-CagA Ab level and FcyRIIA/IIB mRNA expression ratio in monocytes at pretreatment were compared between the H. pylori-infected responders and nonresponders. The FcyRII expression level on monocytes was significantly lower in the responders than in nonresponders (17.2 \pm 4.8 versus $23.4 \pm 8.2 \mathrm{MFI}, P=0.03)$. In addition, the phagocytic capacity and Fc $\gamma$ RIIA/IIB expression ratios of the monocytes were significantly higher in the responders than in the nonresponders $(2.8 \pm 1.5$ versus $1.3 \pm 0.3, P=0.02$; and $1.7 \pm 0.6$ versus $1.1 \pm 0.4, P=0.04)$.

Phenotypic and functional properties of monocytes before and after $H$. pylori eradication in non-ITP subjects. To evaluate whether changes in the phenotypic and functional properties of circulating monocytes after the eradication of $H$. pylori were specific to ITP patients, 9 non-thrombocytopenic volunteers infected with H. pylori were treated with the standard eradication regimen. Erad- an activated monocyte phenotype, i.e., high FcyRI expression, low Fc $\gamma$ RII expression, and enhanced phagocytic capacity, at pretreatment were more likely to respond with improvements in these conditions upon the eradication of $H$. pylori.

Fc $\gamma R$ phenotype on monocytes/macrophages in H. pylori-infected and uninfected mice. We prepared 4 groups of mice ( $n=5$ in each group): $H$. pylori-infected mice, uninfected mice, $H$. pylori-infected mice that had received eradication treatment, and uninfected mice that had received eradication treatment. In mice, there is only one

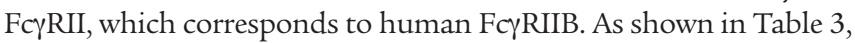
the expression of FcyRII measured using mAb clone 2.4G2 on the monocytes/macrophages derived from peripheral blood, bone marrow, and spleen was significantly lower in mice infected with $H$. pylori than in uninfected mice, while the FcyRI expression tended to be higher in mice infected with $H$. pylori $(P<0.1)$. Both the infected and uninfected mice were given the triple $H$. pylori eradication regimen, and successful eradication was confirmed in all the infected mice by bacterial culture of the stomach at $6 \mathrm{wk}$. In the monocytes/macrophages derived from the peripheral blood, bone marrow, and spleen from these $H$. pylori-eradicated mice, the Fc $\gamma$ RII expression was upregulated and $\mathrm{F}_{\mathrm{C} \gamma \mathrm{RI}}$ expression was downregulated after the eradication. Since mAb clone $2.4 \mathrm{G} 2$ cross-reacts with Fc $\gamma \mathrm{RIII}$, peripheral blood samples were further examined using a mAb specific to Fc $\gamma$ RII (clone Ly17.2) (12). The FcyRII expression level was again significantly lower in $H$. pylori-infected mice compared with mock-treated mice $(3.2 \pm 0.4$ versus $3.9 \pm 0.2 \mathrm{MFI}, P=0.01)$. In $H$. pylori-infected mice, the Fc $\gamma$ RII expression level was increased after the eradication treatment $(3.2 \pm 0.4$ versus $3.9 \pm 0.3 \mathrm{MFI}, P=0.02)$.

\section{Discussion}

In this comprehensive analysis, we demonstrated that the platelet recovery observed in a subset of $H$. pylori-infected ITP patients after $H$. pylori eradication is likely to be mediated through a change in the Fc $\gamma \mathrm{R}$ balance on monocytes/macrophages. An expression level of FcyRII on monocytes was first identified as one of factors associated with $H$. pylori infection in ITP patients by flow cytometric analysis using a mAb that reacts with both FcyRIIA and Fc $\gamma$ RIIB, but this association was later shown to be primarily attributable to inhibitory Fc $\gamma$ RIIB based on 2 different assays: quantitative PCR 


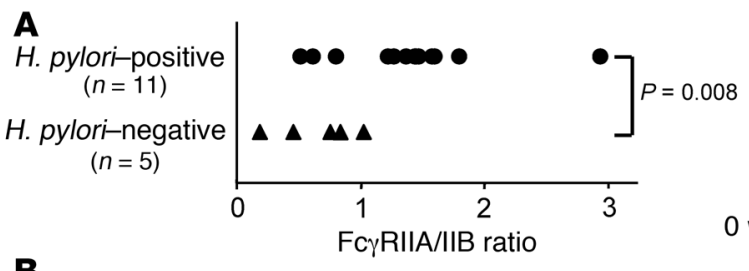

C

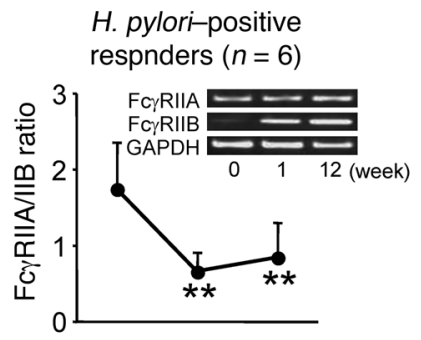

H. pylori-positive

nonrespnders $(n=5)$

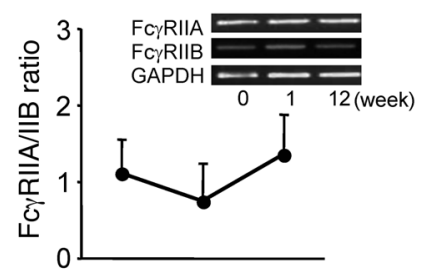

H. pylori-negative

nonrespnders $(n=5)$

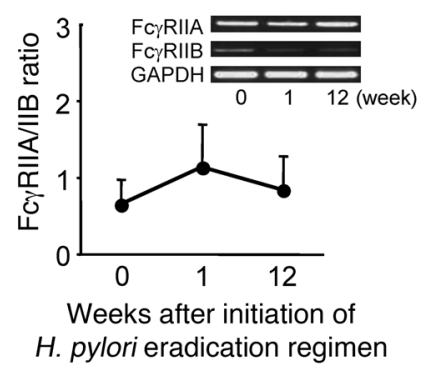

D

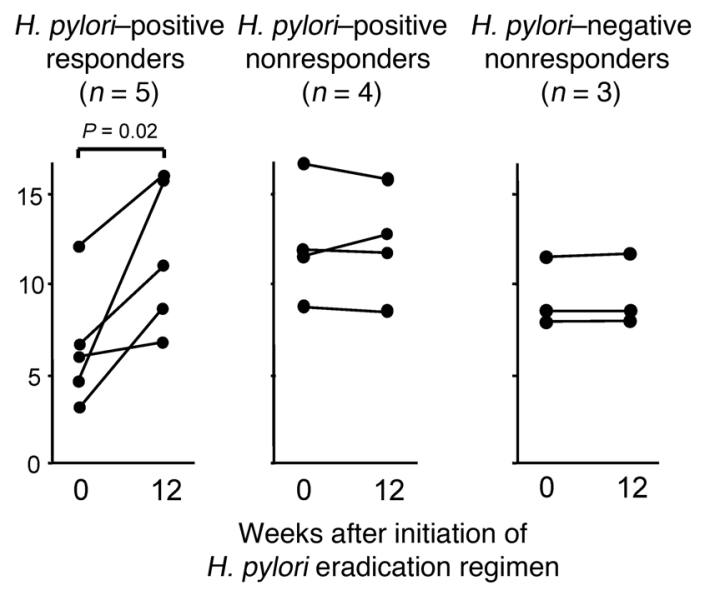

H. pylori-positive $H$. pylori-positive $\begin{aligned} & H \text {. pylori-negative } \\ & \text { responders nonresponders nonresponders }\end{aligned}$

$H$. pylori eradication regimen

\section{Figure 4}

Change in FC $\gamma$ RIIB expression levels in circulating monocytes from ITP patients before and after initiation of the H. pylori eradication. (A) FcyRIIA/IIB mRNA expression ratio on monocytes prior to treatment was determined by quantitative TaqMan PCR in 11 ITP patients infected with $H$. pylori and 5 uninfected ITP patients. The difference between the 2 groups was analyzed using the Mann-Whitney $U$ test. (B) The FcyRIIA/IIB expression ratio on monocytes was serially measured prior to treatment and at 1 and $12 \mathrm{wk}$ after initiation of the $H$. pylori eradication regimen in $6 \mathrm{H}$. pylori-positive ITP responders, $5 \mathrm{H}$. pylori-positive ITP nonresponders, and 5 H. pylori-negative ITP nonresponders. Results are shown as the mean + SD. Changes in the values at 1 and 12 wk from the baseline value taken at wk 0 were assessed by paired $t$ test. ${ }^{* *} P<0.01$ compared with pretreatment. Representative RT-PCR results for the expression of FcyRIIA, FcyRIIB, and GAPDH are shown for each patient group. (C) The protein expression of FcyRIIB on monocytes prior to treatment and 12 wk after initiation of the $H$. pylori eradication regimen in a representative $H$. pylori-positive responder and nonresponder. Open histograms show the cells stained with isotype-matched control $\mathrm{Ab}$, and closed histograms show anti-FcyRIIB mAb-treated cells. (D) Expression levels of Fc $\gamma$ RIIB on monocytes were measured prior to treatment and $12 \mathrm{wk}$ after initiation of the $\mathrm{H}$. pylori eradication regimen in $5 \mathrm{H}$. pylori-positive ITP responders, $4 \mathrm{H}$. pylori-positive ITP nonresponders, and $3 \mathrm{H}$. pylori-negative ITP nonresponders.

for assessment of mRNA expression and flow cytometric analysis using a mAb specific to the intracellular domain of Fc $\gamma$ RIIB. The functional properties of monocytes/macrophages, including phagocytosis and antigen presentation, are controlled by the balance between activating Fcy Rs and an inhibitory receptor, Fc $\gamma$ RIIB
(13). Circulating monocytes from $H$. pylori-infected ITP patients exhibited an activated phenotype with enhanced phagocytic capacity, which potentially resulted from downregulated Fc $\gamma$ RIIB, and this phenotype reverted to that of $H$. pylori-uninfected ITP patients after the eradication of $H$. pylori, but only in the responders. In addition, this change in monocyte phenotype preceded the improvements in autoimmune and platelet kinetic parameters. Therefore, $H$. pylori infection plays an important role in ITP pathogenesis by altering the Fc $\gamma \mathrm{R}$ balance of monocytes/ macrophages in favor of activating Fc $\gamma$ Rs, through downregulation of the inhibitory receptor Fc $\gamma$ RIIB.

Our recent studies on $T$ cells that were autoreactive to GPIIb/IIIa in ITP patients revealed that the pathogenic process of ITP can be explained by a continuous loop in which B cells produce IgG anti-platelet autoantibodies, macrophages in the reticuloendothelial system (RES) phagocytose opsonized platelets via Fc $\gamma$ Rs and present GPIIb/IIIa-derived antigenic peptides, and GPIIb/ IIIa-reactive T cells are activated and exert their helper activity $(14,15)$. It has been shown that anti-GPIIb/IIIa Abs in ITP patients are predominant of the IgG1 subclass (16), which has the highest affinity for Fc $\gamma$ RII (13). Thus, Fc $\gamma$ Rs expressed on macrophages in the RES apparently play a central role in 2 aspects of the pathogenic process: platelet destruction and sustained autoimmune responses to the platelet antigens. It is still debated which activating $\mathrm{Fc} \gamma \mathrm{R}$ is predominantly involved in ITP pathogenesis (17), but the increase in the expression of inhibitory FcyRIIB relative to the activating $F_{c} \gamma$ Rs could eventually result in the attenuation of the pathogenic continuous loop. Therefore, platelet recovery mediated through the upregulated Fc $\gamma$ RIIB expression on monocytes after the eradication of $H$. pylori in ITP patients involves 2 consequent 

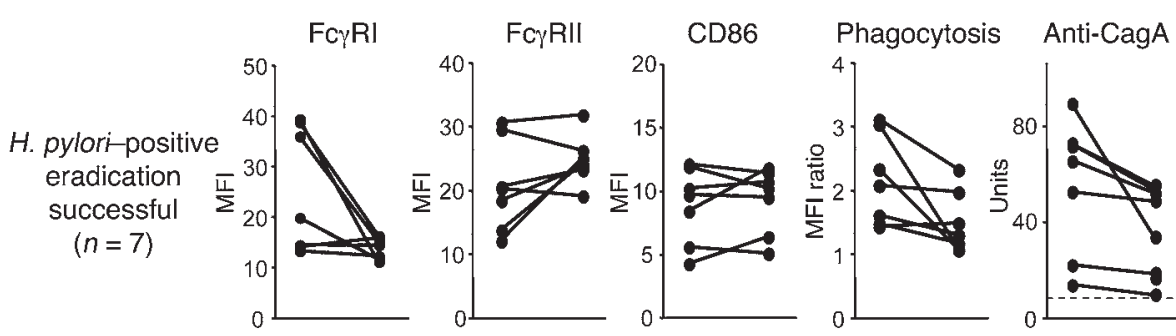

H. pylori-positive
eradication
unsuccessful
$(n=2)$

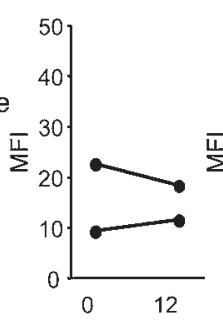

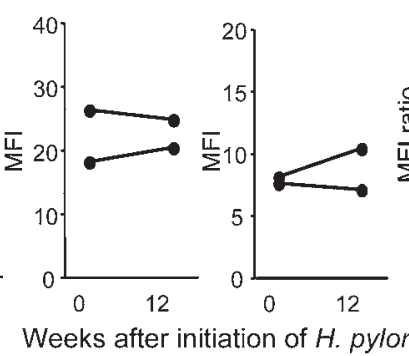

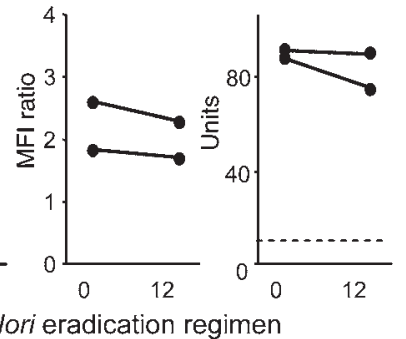

Figure 5

Serial measurements of the phenotype of circulating monocytes and the anti-CagA $\mathrm{Ab}$ level before and after initiation of the $H$. pylori eradication regimen in 9 non-ITP individuals infected with $H$. pylori according to the outcome of the regimen. Expression levels of $\mathrm{Fc} \gamma \mathrm{RI}, \mathrm{Fc} \gamma \mathrm{RII}$ (FcyRIIA plus FC $\gamma R$ IIIB), and CD86, non-specific phagocytosis of circulating monocytes, and antiCagA Ab level were measured prior to treatment and 12 wk after initiation of the $H$. pylori eradication regimen. Expression of $\mathrm{F} c \gamma \mathrm{R}$ Il was examined using $\mathrm{mAb}$ clone FLI8.26, which reacts with both Fc $\gamma R I I A$ and Fc $\gamma R$ IIIB. Results for 7 individuals in which H. pylori was successfully eradicated and for 2 individuals in whom the eradication failed are shown separately. A dotted line indicates the cut-off for anti-CagA Abs (7.5 U). steps: the rapid platelet increase observed at $1 \mathrm{wk}$ is the result of the blockade of platelet clearance by macrophages in the RES, while the sustained platelet increase results from the suppression of antigen presentation by macrophages and the subsequent inhibition of $\mathrm{T}$ and $\mathrm{B}$ cell responses to platelet antigens. To assess the role of $H$. pylori infection on platelet clearance, it is interesting to evaluate whether $H$. pylori infection boosts platelet destruction in mice treated with platelet-depleting mAbs. A similar suppressive effect on the Fc $\gamma$ RIIB expression on macrophages is reported for intravenous immunoglobulin (IVIG). Samuelsson et al. demonstrated that IVIG requires the presence of $\mathrm{Fc} \gamma \mathrm{RIIB}$ to prevent thrombocytopenia in a murine model of passive ITP (18). In this model, Fc $\gamma$ RIIB expression on macrophages was upregulated upon IVIG treatment.

The pathogenesis of ITP in association with $H$. pylori infection is most likely multifactorial. Our mechanism does not exclude other proposed mechanisms for platelet recovery after eradication of $H$. pylori in ITP, such as molecular mimicry between CagA and platelet surface antigens (7). Moreover, it has been shown that some strains of $H$. pylori induce platelet aggregation that is dependent on von Willebrand factor and IgG Abs specific for $H$. pylori interacting with their corresponding receptors GPIb and Fc $\gamma$ RIIA on platelets (19). In this model, Abs specific for $H$. pylori are capa- ble of opsonizing platelets through binding to H. pylori, von Willebrand factor, and GPIb, as are anti-platelet autoantibodies. Thus, decrease in H. pylori-specific Ab levels after the eradication treatment may also suppress presentation of platelet antigens by macrophages. These Ab-mediated mechanisms appear to play a role in the later phase of platelet recovery after the $H$. pylori eradication, since the change in monocyte phenotype preceded the improvements in the $\mathrm{Ab}$ responses to GPIIb/IIIa and CagA.

Platelet recovery after the eradication of $H$. pylori is observed only in a subgroup of $H$. pylori-infected ITP patients $(3,4)$. Our results here indicate that ITP patients with an activated monocyte phenotype, such as an enhanced phagocytic capacity and reduced Fc $\gamma$ RIIB expression, are likely to respond to $H$. pylori eradication, suggesting that the activated monocyte/macrophage phenotype contributes to driving the pathogenic loop that maintains the anti-platelet autoimmune condition in such responders. This finding is clinically important, since an activated monocyte phenotype can predict platelet recovery after the eradication of $H$. pylori in ITP patients. The activation status of circulating monocytes was also heterogeneous in non-ITP individuals infected with H. pylori, and subjects with an activated monocyte phenotype were responsive to H. pylori eradication, which changed the $\mathrm{Fc} \gamma \mathrm{R}$ balance. Thus,

\section{Table 3}

Expression levels of $\mathrm{Fc} \gamma \mathrm{RI}$ and $\mathrm{Fc} \gamma \mathrm{RII}$ on monocytes/macrophages in uninfected mice and mice infected with $H$. pylori after the eradication regimen

\begin{tabular}{|c|c|c|c|c|c|c|c|}
\hline \multirow[b]{2}{*}{$\begin{array}{l}\text { Source of } \\
\text { monocytes }\end{array}$} & \multirow[b]{2}{*}{$\begin{array}{l}\text { H. pylori } \\
\text { infection }\end{array}$} & \multicolumn{3}{|c|}{$\mathrm{F} \mathbf{c} \gamma \mathbf{R I}$} & \multicolumn{3}{|c|}{$\mathbf{F} \mathbf{c} \gamma \mathbf{R} \|^{A}$} \\
\hline & & $\begin{array}{l}\text { Mice without } \\
\text { eradication } \\
\text { treatment }\end{array}$ & $\begin{array}{l}\text { Mice receiving } \\
\text { eradication } \\
\text { treatment }\end{array}$ & $P$ & $\begin{array}{l}\text { Mice without } \\
\text { eradication } \\
\text { treatment }\end{array}$ & $\begin{array}{l}\text { Mice receiving } \\
\text { eradication } \\
\text { treatment }\end{array}$ & $P$ \\
\hline Peripheral blood & $\begin{array}{l}- \\
+\end{array}$ & $\begin{array}{l}234.7 \pm 42.9 \\
270.3 \pm 29.6\end{array}$ & $\begin{array}{l}227.4 \pm 13.7 \\
194.4 \pm 35.5\end{array}$ & $\begin{array}{l}\text { NS } \\
0.05\end{array}$ & $\begin{array}{l}241.8 \pm 46.1^{B} \\
106.6 \pm 32.4^{B}\end{array}$ & $\begin{array}{l}241.0 \pm 78.5 \\
195.0 \pm 26.8\end{array}$ & $\begin{array}{c}\text { NS } \\
0.006\end{array}$ \\
\hline Bone marrow & $\begin{array}{l}- \\
+\end{array}$ & $\begin{array}{r}79.4 \pm 26.3 \\
116.9 \pm 28.4\end{array}$ & $\begin{array}{l}74.8 \pm 28.3 \\
66.6 \pm 13.5\end{array}$ & $\begin{array}{c}\text { NS } \\
0.04\end{array}$ & $\begin{array}{l}343.4 \pm 37.1^{c} \\
228.6 \pm 64.0^{c}\end{array}$ & $\begin{array}{l}361.9 \pm 37.0 \\
306.0 \pm 18.2\end{array}$ & $\begin{array}{l}\text { NS } \\
0.03\end{array}$ \\
\hline Spleen & $\begin{array}{l}- \\
+\end{array}$ & $\begin{array}{r}54.1 \pm 17.0 \\
101.1 \pm 39.2\end{array}$ & $\begin{array}{l}47.2 \pm 9.1 \\
42.0 \pm 7.7\end{array}$ & $\begin{array}{l}\text { NS } \\
0.04\end{array}$ & $\begin{array}{l}451.5 \pm 10.9 c \\
245.5 \pm 35.4 c\end{array}$ & $\begin{array}{l}483.5 \pm 140.7 \\
369.2 \pm 45.0\end{array}$ & $\begin{array}{c}\text { NS } \\
0.001\end{array}$ \\
\hline
\end{tabular}

AMeasured using mAb clone 2.4G2, which cross-reacts with FCy RIII. ${ }^{\mathrm{B}} P<0.05$ and $\mathrm{C} P<0.01$ for the comparison between $H$. pylori-infected and -uninfected groups. - , not infected; +, infected. 
whether H. pylori infection activates the host's monocytes/macrophages differs among individuals independently of the presence or absence of ITP. There is great variability in the efficacy of the $H$. pylori eradication therapy in ITP patients among ethnic groups. Cohorts from Japan and Italy report response rates of 39\%-100\%, while those from Spain and the United States document little to no platelet response (20). The reason for such variability among countries is not clear, but this could be explained by differences in epidemic H. pylori strains or genetic backgrounds among populations. In this regard, H. pylori genotypes were different between the eastern Asian strain and the European strain (21). In addition, genetic factors that regulate the expression of $\mathrm{Fc} \gamma \mathrm{Rs}$ may contribute to this difference. Several polymorphisms exist within the human Fc $\gamma R$ genes that exhibit altered affinities for $\operatorname{IgG}$, potentially resulting in specific allele-dependent clearance rates of immune complexes (22). In particular, one SNP within the Fc $\gamma$ RIIB gene alters its receptor signaling $(23,24)$ and predicts the development of chronic disease in children with acute ITP (25). Another polymorphism in the promoter region of the Fc $\gamma$ RIIB gene downregulates its transcriptional activity (26).

Potential patient selection bias is one of the limitations of this study. Because our hospital is a referral center, many patients had relatively long disease duration and had been treated with prednisolone and/or splenectomy. In addition, our patients were a relatively mild subset, since we excluded patients with active bleeding to minimize dropouts during the study period. We have to consider this potential bias upon interpreting the results, but there was no apparent difference in patient characteristics between H. pylori-infected responders and nonresponders. In addition, the high frequency of splenectomized patients in the H. pylori-negative group might affect the phenotypic and functional properties of circulating monocytes, although there was no apparent difference in the Fc $\gamma$ R expression levels and the phagocytic capacity of monocytes among the $H$. pylori-negative ITP patients regardless of their history of splenectomy (data not shown). Another limitation is the use of peripheral blood monocytes instead of macrophages in the RES in the analysis. However, in mice, H. pylori infection changed the $\mathrm{F} c \gamma \mathrm{R}$ balance similarly in monocytes/macrophages derived from peripheral blood, bone marrow, and spleen, suggesting that circulating monocytes potentially represent the whole monocyte/macrophage system.

The modulation of the monocyte $\mathrm{F} c \gamma \mathrm{R}$ balance associated with H. pylori infection was detected in ITP and non-ITP individuals as well as in mice, indicating that this response might be a normal host immune response against microorganisms that establish chronic infection lasting several decades. It is known that $H$. pylori colonizes the mucous layer of the stomach and does not invade the gastric epithelium, but $H$. pylori infection induces local and systemic responses through stimulation of the innate and adaptive immune systems (27). The molecular events that induce the change in the properties of monocytes/macrophages still remain unclear. We failed to show the role of Th1 response related with $H$. pylori infection in the monocyte phenotype change. On the other hand, it is reported that components of H. pylori are released and are responsible for the activation of dendritic cells and macrophages through toll-like receptor signaling $(28,29)$. In this regard, high frequencies of some specific $H$. pylori genotypes are reported in ITP patients compared with non-ITP subjects (5), suggesting potential roles for the bacterium's structure and virulence profiles in the pathogenesis of ITP.
Previous studies demonstrated a causal link between infection and autoimmune diseases, such as intestinal infections by Campylobacter jejuni and Guillian-Barré syndrome. In this case, Abs crossreacting with lipooligosaccharides present in C. jejuni and in ganglioside GM1 are responsible for development of this disease (30). On the other hand, in ITP patients, H. pylori infection enhanced immunogenicity of platelet-specific autoantigens secondary to infection-mediated Fc $\gamma \mathrm{R}$ balance change of macrophages. A similar mechanism is shown in the animal model for Coxsackie B4 virus-induced type I diabetes (31), in which the virus is thought to act by increasing immunogenicity of autoantigens secondary to local inflammation. In addition, infections may also protect from autoimmune diseases. Onset of type I diabetes was inhibited by helminth parasite infection in animal models (32). A recent randomized, double-blind, placebo-controlled trial demonstrated improvement of active ulcerative colitis by infection with Trichuris suis (33). Effects of infectious agents on the pathogenesis of autoimmunity appear to be variable among diseases, and underlying mechanisms are multiple and complex, probably different according to pathogens.

In summary, $H$. pylori infection plays an important role in the pathogenesis of ITP by altering the $\mathrm{F} c \gamma \mathrm{R}$ balance of monocytes/ macrophages in favor of activating Fc $\gamma$ Rs, through the downregulation of Fc $\gamma$ RIIB. The efficacy and safety profiles of the H. pylori eradication make this regimen an attractive option, but it is indicated only for $H$. pylori-infected patients in certain ethnic groups. The mechanism that induced platelet recovery after $H$. pylori eradication reported here indicates that the $\mathrm{F} c \gamma \mathrm{R}$ balance on monocytes/macrophages may be a reasonable therapeutic target for ITP. In this case, small molecules that inhibit the downstream signal of activating FcyR could have beneficial effects in ITP patients (34). Further studies to evaluate how $H$. pylori infection modulates monocyte/macrophage function may be useful for understanding the pathogenesis of ITP and for developing new therapeutic strategies for ITP.

\section{Methods}

Patients and controls. This was a single-center, open-label, prospective study involving consecutive 34 patients with ITP. The diagnosis of ITP was based on thrombocytopenia persisting longer than $6 \mathrm{mo}$, normal or increased bone marrow megakaryocytes without morphologic evidence of dysplasia, and no secondary immune or non-immune disease that could account for the thrombocytopenic state (35). All the patients were referred to Keio University Hospital, Tokyo, Japan, and had been treated for at least 6 mo. Platelet counts were $<100 \times 10^{9} / 1$ during the preceding 3 mo. The exclusion criteria included age ( $<18 \mathrm{yr}$ ), active bleeding, pregnancy or lactation, a history of potential adverse effects associated with penicillins, current or previous treatment with proton pump inhibitors, or other debilitating illness (e.g., cancer). Nine healthy volunteers infected with $H$. pylori served as control subjects. The study protocol conformed to the ethical principles of the World Medical Association Declaration of Helsinki as reflected in a priori approval from the Keio University Institutional Review Board, and written informed consent was obtained from each participant.

Assessment of $H$. pylori infection. To evaluate $H$. pylori infection, we performed a ${ }^{13} \mathrm{C}$ urea breath test using a UBiT tablet (Otsuka Assay), analyzed serum IgG H. pylori-specific Abs using a commercially available kit (Kyowa Medex Company), and analyzed $H$. pylori antigen in stool samples using ImmunoCard STAT! HpSA (Meridian Bioscience Inc.), in all patients (36). Patients positive for the urea breath test plus at least one additional test were regarded as $H$. pylori positive, whereas those negative for all 3 tests 
were considered H. pylori negative. To minimize false-negative results, patients had not received antacids or antibiotics for at least $2 \mathrm{wk}$ before the tests. Successful eradication was defined as a negative result for the urea breath test $12 \mathrm{wk}$ after the eradication regimen.

H. pylori eradication regimen and follow-up. All patients and controls were given amoxicillin (750 mg twice daily), clarithromycin (400 mg twice daily), and lansoprazole ( $30 \mathrm{mg}$ twice daily) for $7 \mathrm{~d}$ regardless of their $\mathrm{H}$. pylori infection status and were then followed for the subsequent $24 \mathrm{wk}$. The patients were allowed to continue their other therapies during the study period, provided the dosages of drugs were maintained at a constant level until the study was completed, except for prednisolone, which could be decreased or discontinued. A therapeutic response was defined as a platelet count higher than $50 \times 10^{9} / 1$ and doubling of the baseline at $24 \mathrm{wk}$ after initiation of the eradication regimen.

Cell preparation. Heparinized peripheral blood samples were obtained from all subjects at 0 (pre-treatment), 12, and $24 \mathrm{wk}$, and from some patients at $1 \mathrm{wk}$, after initiation of the eradication regimen. After the platelet-rich plasma was isolated, the residual cell components were subjected to Lymphoprep (Nycomed Pharma AS) density gradient centrifugation to isolate the PBMCs. Freshly isolated PBMCs were resuspended in RPMI 1640 containing $10 \%$ heat-inactivated FBS, 2 mmol/l L-glutamine, $50 \mathrm{U} / \mathrm{ml}$ penicillin, and $50 \mu \mathrm{g} / \mathrm{ml}$ streptomycin and were immediately used in the following experiments. Platelet-poor plasma was isolated from plateletrich plasma by centrifugation.

Evaluation of anti-GPIIb/IIIa Ab response. B cells producing IgG anti-GPIIb/ IIIa Abs were detected using the enzyme-linked immunospot assay, as previously described (37). Each experiment was conducted in 5 independent wells, and the results represent the mean of the 5 values. The frequency of circulating anti-GPIIb/IIIa Ab-producing B cells was calculated as the number per $10^{5} \mathrm{PBMCs}$, and the cut-off value was defined as 2.0 cells. IgG anti-GPIIb/IIIa Abs in platelet eluates (from $5 \times 10^{7}$ platelets) were measured by ELISA using purified human GPIIb/IIIa as the antigen (38). Ab units were calculated from the optical density at $450 \mathrm{~nm}\left(\mathrm{OD}_{450}\right)$ results, based on a standard curve obtained from serial concentrations of pooled plasma with high-titer IgG anti-GPIIb/IIIa Abs. All samples were examined in duplicate, and the results were calculated as the mean of the 2 values. The cut-off for platelet-associated anti-GPIIb/IIIa Abs was $3.3 \mathrm{U}$.

Evaluation of $T$ cell response to GPIIb/IIIa. The antigenic specificity of $\mathrm{T}$ cells was determined by antigen-induced $\mathrm{T}$ cell proliferation as previously described (39). Briefly, PBMCs were cultured in the presence or absence of antigen for $7 \mathrm{~d}$. After a final $16-\mathrm{h}$ incubation with $0.5 \mu \mathrm{Ci} /$ well ${ }^{3} \mathrm{H}$-thymidine, the cells were harvested, and the ${ }^{3} \mathrm{H}$-thymidine incorporation was determined in a TopCount microplate scintillation counter (Packard). Antigens used were trypsin-digested GPIIb/IIIa, mock-treated PBS, and tetanus toxoid (List Biological Laboratories) used at a concentration of $5 \mu \mathrm{g} / \mathrm{ml}$. All the cultures were prepared in triplicate, and all the values represent the mean of triplicate determinations. Antigen-specific $\mathrm{T}$ cell response was expressed as the stimulation index, which was calculated as the cpm incorporated into cultures with trypsin-digested GPIIb/IIIa or tetanus toxoid divided by the cpm incorporated into cultures with mock treatment with PBS.

Evaluation of platelet turnover. Reticulated platelets were detected by staining freshly isolated platelets with thiazole orange (Retic-COUNT; Becton Dickinson) followed by flow cytometric analysis, as described previously (40). The cut-off for the percentage of reticulated platelets was $2.0 \%$. The plasma TPO level was measured using a commercially available ELISA kit (Quantikine; R\&D Systems) according to the manufacturer's protocol.

Evaluation of phenotypic and functional properties of circulating monocytes. Unfixed PBMCs were stained with FITC-conjugated anti-FcyRI/CD64 (clone 10.1), anti-FcrRII/CD32 (clone FLI8.26), anti-FcrRIII/CD16 (clone 3G8) (BD Biosciences), or anti-CD86 mAbs (clone BU63; Ancell), in com- bination with PC5-conjugated anti-CD14 mAb (clone RMO52; Beckman Coulter). For Fc $\gamma$ RIIB staining, the cells were fixed and permeabilized using a buffer containing paraformaldehyde and saponin (BD Biosciences) and subsequently stained with mAbs to the C-terminal portion of Fcy RIIB (clone EP888Y; Epitomics), followed by incubation with FITC-labeled anti-rabbit IgG F $\left(\mathrm{ab}^{\prime}\right)_{2}$ (Beckman Coulter) and PC5-conjugated anti-CD14 $\mathrm{mAb}$. The negative controls were cells incubated with fluorescent-labeled isotype-matched mouse mAbs against an irrelevant antigen. The cells were analyzed on a FACSCalibur flow cytometer (BD Biosciences) using CellQuest software. Viable cells were selected by the exclusion of apoptotic cells stained with propidium iodide (Sigma-Aldrich). Relative expression levels of Fc $\gamma$ RI, Fc $\gamma$ RII (Fc $\gamma$ RIIA plus Fc $\gamma$ RIIB), Fc $\gamma$ RIIB, Fc $\gamma$ RIII, and CD86 on gated $\mathrm{CD} 14^{+}$monocytes were expressed as MFI, which was calculated based on the intensity of the cells incubated with appropriate isotypematched control $\mathrm{mAb}$ as a reference. The proportion of cells positive for FcyRIII in CD14 $4^{+}$monocytes was also determined. Each assay included a quality control PBMC sample derived from a single healthy donor, which had been stored in aliquots at $-80^{\circ} \mathrm{C}$. The nonspecific phagocytic capacity of monocytes was examined as described previously (41). In brief, PBMCs were cultured with neutral FITC-dextran with a molecular weight of 2,000 $\mathrm{kDa}$ (Sigma-Aldrich) for $30 \mathrm{~min}$ at $0^{\circ} \mathrm{C}$ or $37^{\circ} \mathrm{C}$ and analyzed on a flow cytometer. The uptake of FITC-labeled dextran was evaluated by MFI on gated $\mathrm{CD} 14^{+}$monocytes. The phagocytic capacity was expressed as an MFI ratio, which was calculated as the MFI obtained at $37^{\circ} \mathrm{C}$ divided by the MFI at $0^{\circ} \mathrm{C}$. Consistent settings for detector sensitivity, compensation, and scatter gating were used in the analyses of all the samples.

Th1/Th2 balance. Proportions of IFN- $\gamma^{+}$cells and IL- $4^{+}$cells in peripheral blood $\mathrm{CD}^{+} \mathrm{T}$ cells were evaluated using flow cytometry-based Intracellular Cytokine Staining Kit Human (BD Biosciences) according to the manufacturer's protocol. The results were expressed as the ratio of IFN $-\gamma^{+} \mathrm{CD} 4^{+}$ T cells to IL- $4^{+} \mathrm{CD} 4^{+} \mathrm{T}$ cells.

Anti-CagA Abs. Anti-CagA Abs of the IgG isotype were measured in duplicate in plasma samples using a commercially available ELISA kit (ravo Diagnostika). The cut-off of $7.5 \mathrm{U}$ was based on the manufacturer's information.

Gene expression of Fc $\gamma$ RIIA and Fcy RIIB on monocytes. Circulating CD $14^{+}$ monocytes were isolated from PBMCs using an anti-CD14 mAb coupled to magnetic beads (Miltenyi Biotech) followed by MACS column separation. Flow cytometric analysis revealed that the sorted fractions contained $>95 \%$ $\mathrm{CD} 14^{+}$cells. Total RNA was extracted from monocytes using the RNeasy kit (Qiagen), and first-strand cDNA synthesized from the total RNA was subjected to PCR using a panel of specific primers (Fc $\gamma$ RIIA: sense primer, 5'-CTGACTGTGCTTTCCGAATG-3', and antisense primer, 5'-TGGATGAGAACAGCGTGTAG-3'; Fc $\gamma$ RIIB: sense primer, 5'-ACAAGCCTCTGGTCAAGGTC- $3^{\prime}$, and antisense primer, $5^{\prime}$-TTCCCTGCACTCAGGGTATC-3'; and GAPDH: sense primer, $5^{\prime}$-TGAACGGGAAGCTCACTGG - $3^{\prime}$, and antisense primer, $5^{\prime}$-TCCACCACCCTGTTGCTGTA-3'). The PCR products were resolved by electrophoresis on $2 \%$ agarose gels and visualized by ethidium bromide staining. In addition, mRNA expression levels were quantitatively assessed using the TaqMan real-time PCR system (Applied Biosystems). A combination of primers and a probe specific for human FcyRIIA and FcyRIIB was purchased from Applied Biosystems. The relative expression levels were calculated from a standard curve generated by plotting the amount of PCR product against the serial amount of input PBMC CDNA, and the FC $\gamma$ RIIA/IIB ratio was calculated from the relative expression levels in the same sample.

Infection and eradication of $H$. pylori in mice. Six-week-old, specific pathogen-free male mice (C57BL/6; Sankyo Lab Service) were given irradiated food and autoclaved distilled water ad libitum. The Sydney strain of H. pylori SS1, which was grown at $37^{\circ} \mathrm{C}$ under microaerobic conditions, was used for oral inoculation, as described previously $(42,43)$. Suspensions of 
H. pylori $\left(2 \times 10^{7} \mathrm{CFU} / \mathrm{ml}, 15 \mathrm{ml} / \mathrm{kg}\right)$ were administered to mice after overnight starvation, twice with a 2 -wk interval, while control mice received suspensions of buffer solution alone (mock infection). Twelve weeks later, half of the mice in the H. pylori-inoculated group and the control group were sacrificed for examination. The remaining $H$. pylori-inoculated and control mice were treated with the $H$. pylori eradication treatment consisting of lansoprazole $(10 \mathrm{mg} / \mathrm{kg})$, amoxicillin $(3 \mathrm{mg} / \mathrm{kg})$, and clarithromycin $(30 \mathrm{mg} / \mathrm{kg}$ ) suspended in $0.5 \%$ carboxymethyl cellulose sodium salt solution, once a day for $2 \mathrm{~d}$ (44). Six weeks later, all the mice were sacrificed for examination. H. pylori infection in the excised stomach was evaluated by microaerobic bacterial culture, as previously described (45). Mononuclear cells were isolated from the peripheral blood, spleen, and bone marrow and stored at $-80^{\circ} \mathrm{C}$, and all samples were subjected to flow cytometric analysis on the same day. Cells were incubated with a Cy5-labeled antimouse CD11b mAb (clone M1/70; Beckman-Coulter) in combination with a biotin-labeled anti-mouse Fc $\gamma$ RI polyclonal Ab (R\&D Systems) or a rat $\mathrm{mAb}$ reactive with both mouse Fc $\gamma \mathrm{RII}$ (clone 2.4G2; BD Biosciences - Pharmingen) and biotin-labeled anti-rat IgG (Jackson ImmunoResearch Laboratories Inc.), followed by treatment with FITC-streptavidin (Beckman Coulter). In some instances, we used a mouse mAb specific to FcyRII (clone Ly17.2) (Sloan-Kettering Cancer Institute) in combination with FITC-labeled anti-mouse IgG F $\left(\mathrm{ab}^{\prime}\right)_{2}$. All mouse procedures were approved by the Keio University Animal Research Committee.
Statistics. All continuous values are shown as the mean \pm SD. Comparisons to determine the statistical significance between 2 groups were performed using the Fisher's Exact test or Mann-Whitney $U$ test, as appropriate. Changes in the absolute values at different time points from the baseline value taken at week 0 were compared by paired $t$ test.

\section{Acknowledgments}

We thank Ulrich Hammerling (Sloan-Kettering Institute) for coordinating acquisition of mAb clone Ly17.2 and Masahiro Kizaki and Mitsuru Murata for recruiting the patients for this study. This work was supported by a grant from the Japanese Ministry of Education, Culture, Sports, Science and Technology, a research grant on intractable diseases from the Japanese Ministry of Health, Labour and Welfare, and the Nagao Memorial Fund.

Received for publication November 14, 2007, and accepted in revised form May 14, 2008.

Address correspondence to: Masataka Kuwana, Division of Rheumatology, Department of Internal Medicine, Keio University School of Medicine, 35 Shinanomachi, Shinjuku-ku, Tokyo 1608582, Japan. Phone: 81-3-3350-3567; Fax: 81-3-3350-3567; E-mail: kuwanam@sc.itc.keio.ac.jp.
1. Cines, D.B., Blanchette, V.S., Mannucci, P.M., Remuzzi, G., and Clines, D.B. 2002. Immune thrombocytopenic purpura. N. Engl. J. Med. 346:995-1008.

2. Gasbarrini, A., et al. 1998. Regression of autoimmune thrombocytopenia after eradication of Helicobacter pylori. Lancet. 352:878.

3. Fujimura, K., et al. 2005. Is eradication therapy useful as the first line of treatment in Helicobacter pylori-positive idiopathic thrombocytopenic purpura? Analysis of 207 eradicated chronic ITP cases in Japan. Int. J. Hematol. 81:162-168.

4. Franchini, M., and Veneri, D. 2006. Helicobacter pylori-associated immune thrombocytopenia. Platelets. 17:71-77.

5. Emilia, G., et al. 2007. Helicobacter pylori infection and chronic immune thrombocytopenic purpura: long-term results of bacterium eradication and association with bacterium virulence profiles. Blood. 110:3833-3841.

6. Asahi, A., et al. 2006. Effects of Helicobacter pylori eradication regimen on anti-platelet autoantibody response in infected and uninfected patients with idiopathic thrombocytopenic purpura. Haematologica. 91:1436-1437.

7. Takahashi, T., et al. 2004. Molecular mimicry by Helicobacter pylori CagA protein may be involved in the pathogenesis of $H$. pylori-associated chronic idiopathic thrombocytopenic purpura. Br. J. Haematol. 124:91-96.

8. Michel, M., et al. 2002. Autoimmune thrombocytopenic purpura and Helicobacter pylori infection. Arch. Intern. Med. 162:1033-1036.

9. Yamanishi, S., et al. 2006. Implications for induction of autoimmunity via activation of B-1 cells by Helicobacter pylori urease. Infect. Immun. 74:248-256.

10. Pellicano, R., et al. 2004. Prevalence of non-organspecific autoantibodies in patients suffering from duodenal ulcer with and without Helicobacter pylori infection. Dig. Dis. Sci. 49:395-398.

11. Pricop, L., et al. 2001. Differential modulation of stimulatory and inhibitory $\mathrm{Fc}_{\mathrm{c}}$ receptors on human monocytes by Th1 and Th2 cytokines. J. Immunol. 166:531-537.

12. Schiller, C., et al. 2000. Mouse F $\gamma \gamma$ RII is a negative regulator of Fcy RIII in IgG immune complex-triggered inflammation but not in autoantibody- induced hemolysis. Eur. J. Immunol. 30:481-489.

13. Takai, T. 2002. Roles of Fc receptors in autoimmunity. Nat. Rev. Immunol. 2:580-592.

14. Kuwana, M., and Ikeda, Y. 2005. The role of autoreactive T-cells in the pathogenesis of ITP. Int. J. Hematol. 81:106-112.

15. Kuwana, M., Kawakami, Y., and Ikeda, Y. 2005. Splenic macrophages maintain the anti-platelet autoimmune response via uptake of opsonized platelets in patients with chronic ITP [abstract]. Blood. 106(Suppl.):68a.

16. Chan, H., Moore, J.C., Finch, C.N., Warkentin, T.E., and Kelton, J.G. 2003. The IgG subclasses of platelet-associated autoantibodies directed against platelet glycoproteins IIb/IIIa in patients with idiopathic thrombocytopenic purpura. Br. J. Haematol. 122:818-824.

17. Crow, A.R., and Lazarus, A.H. 2003. Role of Fc $\gamma$ receptors in the pathogenesis and treatment of idiopathic thrombocytopenic purpura. J. Pediatr. Hematol. Oncol. 25(Suppl. 1):S14-S18.

18. Samuelsson, A., Towers, T.L., and Ravetch, J.V. 2001. Anti-inflammatory activity of IVIG mediated through the inhibitory Fc receptor. Science. 291:484-486.

19. Byrne, M.F., et al. 2003. Helicobacter pylori binds von Willebrand factor and interacts with GPIb to induce platelet aggregation. Gastroenterology. 124:1846-1854.

20. Kuwana, M., and Ikeda, Y. 2006. Helicobacter pylori and immune thrombocytopenic purpura: unsolved questions and controversies. Int. J. Hematol. 84:309-315.

21. Azuma, T. 2004. Helicobacter pylori CagA protein variation associated with gastric cancer in Asia. J. Gastroenterol. 39:97-103.

22. van der Pol, W., and van de Winkel, J.G. 1998. IgG receptor polymorphisms: risk factors for disease. Immunogenetics. 48:222-232.

23. Li, X., et al. 2003. A novel polymorphism in the Fcy receptor IIB (CD32B) transmembrane region alters receptor signaling. Arthritis Rheum. 48:3242-3252.

24. Floto, R.A., et al. 2005. Loss of function of a lupusassociated $\mathrm{Fc} \gamma \mathrm{RIIb}$ polymorphism through exclusion from lipid rafts. Nat. Med. 11:1056-1058.

25. Bruin, M., et al. 2004. Platelet count, previous infection and FCGR2B genotype predict development of chronic disease in newly diagnosed idiopathic thrombocytopenia in childhood: results of a prospective study. Br. J. Haematol. 127:561-567.

26. Su, K., et al. 2004. A promoter haplotype of the immunoreceptor tyrosine-based inhibitory motifbearing Fc $\gamma$ RIIb alters receptor expression and associates with autoimmunity. II. Differential binding of GATA4 and Yin-Yang1 transcription factors and correlated receptor expression and function. J. Immunol. 172:7192-7199.

27. Ernst, P.B., and Gold, B.D. 2000. The disease spectrum of Helicobacter pylori: the immunopathogenesis of gastroduodenal ulcer and gastric cancer. Annu. Rev. Microbiol. 54:615-640.

28. Ferrero, R.L. 2005. Innate immune recognition of the extracellular mucosal pathogen, Helicobacter pylori. Mol. Immunol. 42:879-885.

29. Rad, R., et al. 2007. Toll-like receptor-dependent activation of antigen-presenting cells affects adaptive immunity to Helicobacter pylori. Gastroenterology. 133:150-163.

30. Yuki, N., et al. 2004. Carbohydrate mimicry between human ganglioside GM1 and Campylobacter jejuni lipooligosaccharide causes Guillain-Barré syndrome. Proc. Natl. Acad. Sci. U. S. A. 101:11404-11409.

31. Horwitz, M.S., et al. 1998. Diabetes induced by Coxsackie virus: initiation by bystander damage and not molecular mimicry. Nat. Med. 4:781-785.

32. Saunders, K.A., Raine, T., Cooke, A., and Lawrence, C.E. 2007. Inhibition of autoimmune type 1 diabetes by gastrointestinal helminth infection. Infect. Immun. 75:397-407.

33. Summers, R.W., Elliott, D.E., Urban, J.F., Jr., Thompson, R.A., and Weinstock, J.V. 2005. Trichuris suis therapy for active ulcerative colitis: a randomized controlled trial. Gastroenterology. 128:825-832.

34. Braselmann, S., et al. 2006. R406, an orally available spleen tyrosine kinase inhibitor blocks Fc receptor signaling and reduces immune complexmediated inflammation. J. Pharmacol. Exp. Ther. 319:998-1008.

35. George, J.N., et al. 1996. Idiopathic thrombocytopenic purpura: A practice guideline developed by explicit methods for the American Society of Hematology. Blood. 88:3-40.

36. Suzuki, H., Hibi, T., and Marshall, B.J. 2007. Helico- 
bacter pylori: present status and future prospects in Japan. J. Gastroenterol. 42:1-15.

37. Kuwana, M., Okazaki, Y., Kaburaki, J., and Ikeda, Y. 2003. Detection of circulating B cells secreting platelet-specific autoantibody is a sensitive and specific test for the diagnosis of autoimmune thrombocytopenia. Am. J. Med. 114:322-325.

38. Kuwana, M., Okazaki, Y., Kaburaki, J., Kawakami, Y., and Ikeda, Y. 2002. Spleen is a primary site for activation of platelet-reactive $\mathrm{T}$ and $\mathrm{B}$ cells in patients with immune thrombocytopenic purpura. J. Immunol. 168:3675-3682.
39. Kuwana, M., et al. 2001. Immunodominant epitopes on glycoprotein IIb-IIIa recognized by autoreactive $T$ cells in patients with immune thrombocytopenic purpura. Blood. 98:130-139.

40. Kuwana, M., et al. 2005. Initial laboratory findings useful for predicting the diagnosis of idiopathic thrombocytopenic purpura. Am. J. Med. 118:1026-1033.

41. Takahara, K., et al. 2004. Functional comparison of the mouse DC-SIGN, SIGNR1, SIGNR3 and Langerin, C-type lectins. Int. Immunol. 16:819-829.

42. Lee, A., et al. 1997. A standardized mouse model of
Helicobacter pylori infection: Introducing the Sydney strain. Gastroenterology. 112:1386-1397.

43. Suzuki, H., et al. 2002. Attenuated apoptosis in $H$. pylori-colonized gastric mucosa of Mongolian gerbils in comparison with mice. Dig. Dis. Sci. 47:90-99.

44. Shimizu, N., et al. 2000. Eradication diminishes enhancing effects of Helicobacter pylori infection on glandular stomach carcinogenesis in Mongolian gerbils. Cancer Res. 60:1512-1514.

45. Suzuki, H., et al. 1999. H. pylori-associated gastric pro- and anti-oxidant formation in Mongolian gerbils. Free Radic. Biol. Med. 26:679-684. 